\title{
Validity and timing in decision support systems
}

JEL: 034 DOI: 10.24136/atest.2018.562

Data zgłoszenia: 19.11.2018 Data akceptacji: 15.12.2018

Based on the principle of synthesizing the matrix of transitional probabilities, processes of decision-making support by means of the truncated procedures of type $(k / n)_{n}(k \leq n)$ are considered. Obtained expressions for calculating the time-efficiency of the processes of decision support using procedures type $(k / 4)_{4}$ are shown. There are given calculated by the expressions obtained data time efficiency, which will enable a quantitative comparison between different procedures and select the best of them on the basis of specific practical tasks.

Słowa kluczowe: decision support systems, validity, timing, process.

\section{Introduction}

Validity is the fundamental concept of the theory decisionmaking and characterizes their quality. In the theoretical plan validity is defined by completeness and reliability of basic data, depth of scientific knowledge of regularities relating to the operated processes, quality of the mathematical models used at development of decisions and specific features of the particular making decision person [1],[12],[13] (P, MD) - experience, intuition, knowledge, etc.

In difference from the efficiency determined by physically obvious and directly measurable values of phase duration managements, validity the difficult and much less studied concept. Special practical value is gained by a validity assessment in the decisionmaking support systems (DMSS-Decision Making Support System) in which the system forms possible versions of decisions. They are qualitatively new level of automating administrative processes. DMSS develop administrative information systems to high extent of intellectualization of activity at decision-making in the problem situations which are characterized by big complexity, uncertainty and weak structure.

DMSS represents a complex of technical means (program and hardware), intended for performance of expert functions in the situations demanding adoption of the proved and qualified decisions $[1,12,13]$ both in usual, and in extreme and non-staff conditions. Proceeding from it when developing DMSS a main objective is creation of programs (devices) which at the solution of the tasks difficult for the expert (person), reach validity, quality and efficiency of the solutions proposed by system, and the final decision is made by the expert (person) and bears full responsibility for consequences from his realization. Therefore at creation of DMSS usually use three principles [1]:

- power of system depends on information volume in the knowledge base in the beginning, and then is defined by the procedures of result formation used in it i.e., it is important to have knowledge, sufficient for solvable tasks, but not difficult procedures of a conclusion of the decision;

- knowledge of the expert is generally heuristic, uncertain, plausible, but not true. It speaks, the fact that solvable tasks, are difficult formalizable. Knowledge of the expert has subjective character. Often the expert up to the end does not realize as he solves an objective;
_ in connection with difficult formalizability of solvable tasks with heuristic subjective nature of the used knowledge the object of management has to participate in the direct interaction with DMSS proceeding in the form of dialogue.

Functioning of DMSS [13] can be divided into three stages:

- knowledge acquisition;

- the organization of knowledge ensuring effective functioning of system;

- delivery of knowledge, at the request of management object. Use of DMSS has the following features [1]:

- the system is applied to the solution of difficult practical tasks

- quality, validity and efficiency of solutions of DMSS should not concede to decisions of the person (expert);

- solutions of DMSS have to be clear at the qualitative level;

- systems are capable to fill up the knowledge during dialogue.

Therefore the assessment of time and efficiency of processes of decision-making is very important.

\section{Work Purpose}

The article purpose is consideration of possible methodical receptions to an assessment of validity and to give a comparative assessment them, and also to receive expressions for calculation of temporary efficiency of processes of decision-making support by means of the truncated procedures [12].

\section{Main Part}

Now in scientific literature the applied three groups of methods of an assessment of validity are described.

The first group of methods is based on a posteriori assessment of validity, i.e. an assessment of versions of the decision on their consequences.

Value of validity is determined as extent of approach of the formed option to optimum by value of criterion of efficiency of the operated process, i.e. external criterion of management $[2,11]$.

In this method expression of determination of validity is used $\theta(x)$.

$$
\theta(x)=1-\left[P\left(x_{0}\right)-P(x) / P\left(x_{0}\right)\right],
$$

where $P(x)_{\text {- efficiency of the operated process at the chosen }}$ version of decisions ${ }^{x} ; P\left(x_{0}\right)$ - the maximum value of efficiency of the operated process reached at the choice of an optimal variant of decisions ${ }^{x_{0}}$.

As $P\left(x_{0}\right) \geq P(x)$ the ratio (1) is always fair $\theta(x) \leq 1$, and equality $\theta(x)=1$ is reached only at coincidence of the chosen decision with optimum.

Kind of this group of methods is the method which is based on a correlation coefficient assessment $K(P, \theta)$ between the reached management efficiency $P(x)$ and value of validity $\theta$ [2].

$$
K(P, \theta)=\frac{\{p-M(P)\}\{\theta-M(\theta)\}}{\sigma_{p} \sigma_{\theta}},
$$

where $M(P), M(\theta)$ - population mean of sizes $P_{y}, \theta_{p} \sigma_{p}, \sigma_{\theta}$ - their mean square deviation.

\section{AUTOBUSY12/2018}


As $0 \leq K(P, \theta) \leq 1$, at an optimal variant of the decision $K(P, \theta)$ will be close to unit.

By external criterion the following shortcomings are inherent in a validity assessment:

It is necessary to know optimum value of the operated process efficiency $P\left(x_{0}\right)$. For this purpose further research by means of special mathematical models or imitating modeling is necessary that can be comparable on complexity and time with the solution of the main objective.

In this group of methods incompleteness and inaccuracy of information on object of management and external conditions is not considered that often leads to emergence not of one, but sets (area) of optimal solutions. Therefore any determination of the decision validity has to be based taking into account uncertainty of basic data.

The second group of methods is represented by alternative methods. In an alternative method $[3,10,11]$ the person makes the decision in the course of justification analyzes a number of options on area of admissible values. Depending on degree of uncertainty which usually contains in basic data and specific human features HDM (human decision maker) defines number of options mtask, which he considers expedient to analyses for justification of the decision. The actual number of the considered options $m$ depends on resources and time for decision-making. It can appear less than mtask. As a measure of decisions validity the relation of number of actually considered options $\mathrm{m}$ to the set number mtask is used:

$$
\theta(m)=m / m_{\text {task }}
$$

It is impossible to recognize such approach satisfactory for the following three basic reasons.

The results received based on the ratio of (3) in a decisive way depends on subjectively set value mtask. If HDM - the person insufficiently far-sighted, then it sets small number of options, but from here contrary to a ratio (3), it is impossible to draw a conclusion on high validity of the decision in any way.

The validity calculated based on the ratio of (3) does not possess property of saturability. It means that at any number of the options, which are already considered by HDM in the range of values $m \in\left[1, m_{\text {task }}-1\right]$ according to expression (3) expediently further carrying out researches, and a gain of validity values is identical in areas of both small, and great values $m$.

Theoretically value of validity cannot reach the value equal to unit. At any the volume and depth of justification, there is always an opportunity to consider additional data and by that to improve quality of the made decision. However based on the ratio of (3) value of validity at $m=m_{\text {task }}$ equally to unit, from this it follows that research on bigger, than $m_{\text {task, }}$, to number of options it is inexpedient. As value $m_{\text {task }}$ it is set for subjective reasons and consequently it cannot coincide with almost expedient number of options. Therefore use of expression (3) can lead in practice to incorrect recommendations.

The third group of methods - probabilistic (statistical) methods of an assessment of validity at which a basis of methods is the fact that the most essential factor of the made decisions validity is completeness (volume) of initial information and its availability.

Statistical methods of validity assessment are based on the assumption that validity is defined by the statistics volume which are estimated from the point of view of their validity [14].
In this case validity is defined according to the limit theorem of Jacob Bernoulli $[4,11,14]$.

$$
\begin{aligned}
& \quad P\left(\left|\theta^{*}-\theta\right|<\varepsilon\right)>1-\delta_{i} \\
& \lim _{n \rightarrow \infty} P=1
\end{aligned}
$$

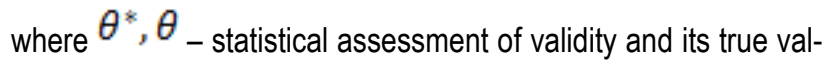
ue respectively; $\varepsilon_{,} \delta$ - very small positive numbers.

According to [3], for any difficult control system increase in volume of initial information leads to increase of validity of the made decisions according to expression:

$$
\theta=\theta\left(1-B_{0} e^{-I / I_{0}}\right)_{\max }
$$

where I - the number of the available information; $\theta_{\max }$ - validity of decisions at full and exact information, i.e. $\theta_{\max } ; B_{0-}$ amount of entropy - uncertainty of the made decisions, obviously $B_{0}=1-\theta_{0} ; \theta_{-}$aprioristic probability of awareness.

Then degree of validity of decisions is defined by a ratio:

$$
\theta=1-\left(1-\theta_{0}\right) e^{-\gamma I}
$$

where $\gamma$ - a component, the characterizing information value from the point of view of the made decisions.

Really, size $\gamma=\frac{1}{I_{0}}$ speed of increase of size is characterized $\theta$ depending on the volume of the used information.

Other option of a probabilistic method of validity determination is given in work [5, 14]. According to this method, validity is defined as probability of a right choice (optimum) decision. At the same time validity of the decision by consideration $m$ options it is equal

$$
\begin{gathered}
\theta-1=e^{-\alpha m} \quad(7) \\
\text { where : } \alpha=-\operatorname{Ln}\left\{1-\frac{1}{m_{0}}\left[2 \Phi_{0}(\varepsilon / \Delta)^{U-M}\right]\right\} ; \\
\Phi_{0}(x)=\frac{1}{\sqrt{2 \pi}} \int_{0}^{x} \exp \left(-\frac{t^{2}}{2}\right) d t \text { - Gauss's interval; } \\
\mathrm{U}-\text { number of management parameters ; } \\
\Delta-\Delta_{e}(e=\overline{1, U}) \text { - a mean square deviation of management }
\end{gathered}
$$
parameters from the extreme values inherent in optimal solutions; $\varepsilon$ - change interval $\Delta$, i.e. $-\varepsilon \leq \Delta \leq \varepsilon$; M - number of not optimized parameters; $m_{0}$ - number of options which have to be analyzed for definition of the optimal solution.

To the considered methods of assessment decision validity have the common fault inherent in all i.e. they do not allow to estimate and recommend to HDM version of the decision optimum of those options which are prepared in the course of functioning of DMSS.

In this regard we will consider in more detail process of formatting the decision versions and an assessment of their validity in DMSS. For definiteness we will take DMSS in which the indistinct productional knowledge base are realized [6].

Let's consider known:

- set of decisions $D=\left\{d_{1}, d_{2}, d_{3}, \ldots, d_{m}\right\}$, corresponding to output variables y; 
- set of entrance variables $X=\left\{x_{1}, x_{2}, x_{3}, \ldots, x_{n}\right\}$.

- ranges of quantitative change of each entrance variable $x_{i} \in\left\{x_{i}, \overline{x_{i}}\right\}, i=\overline{1, n}$

- function of accessory $\mu\left(x_{i}\right)$, allowing to represent variables $x_{i}, i=\overline{1, n}$ in the form of odd sets.

It is required: to develop the algorithm of decision-making allowing to make decisions on the fixed vector of entrance variables $X^{*}=\left\langle x_{1}{ }^{*}, x_{2}{ }^{*}, x_{3}{ }^{*}, \ldots, x_{n}{ }^{*}\right\rangle, x_{1}^{*} \in\left[x_{i}, \overline{x_{i}}\right]$ to put the decision in compliance $y \in D$

For the solution of this task the indistinct logical equations which are under construction on the basis of a knowledge matrix are used and allow to calculate functions of accessory relating to various decisions $\mu(d)$ at the fixed values of entrance variables.

The system of the logical equations briefly can be written down as follows [3]:

$$
\mu^{d_{i}}\left(x_{1}, x_{2}, x_{3}, \ldots, x_{n}\right)=
$$

where $\mu^{\alpha_{i}^{j_{p}}}\left(x_{i}\right)$ - function of accessory of parameter $x_{\tilde{i}}$ to indistinct term $\alpha_{i}^{j_{p}}$, $i=\overline{1, n} \cdot j=\overline{1, m} ; p=\overline{1, K} ; \mu^{\alpha_{j}}\left(x_{1}, x_{2}, x_{3}, \ldots, x_{n}\right)$. function of accessory of a vector of input parameters $X\left(x_{1}, x_{2}, x_{3}, \ldots, x_{n}\right)$ to value of an output variable $y=d_{i} ; j=\overline{1, m}$.

As the required decision HDM the decision with the greatest value of accessory function recommended. At the same time the specified value conditionally is accepted to degree of validity of decisions. More testing and validity of DMSS can be read in Sailors et.al. [10] and Pomerol [12] and Box [14]. tions:

The algorithm of decision-making contains the following opera-

1 operation. The vector of values of entrance variables is set $X^{*}=\left\langle x_{1}{ }^{*}, x_{2}{ }^{*}, x_{3}{ }^{*}, \ldots, x_{n}{ }^{*}\right\rangle$.

2 operation. Functions of accessory of indistinct terms are set and values of these functions for preset values of entrance variables are defined $x_{1}^{*} \div x_{n}^{*}$.

3 operation. Using the logical equations (8) functions of accessory are calculated $\mu^{d_{j}}\left(x_{1}^{*}, x_{2}^{*}, x_{3}^{*}, \ldots, x_{n}^{*}\right)$ vector $X^{*}$ for all values $d_{j}, j=\overline{1, m}$. At the same time logical operations AND $(\mathrm{n})$ and $\mathrm{OR}(\mathrm{U})$ over functions of accessory are replaced with operations min and max

$$
\begin{aligned}
& \mu(a) \cap \mu(b)=\min [\mu(\alpha), \mu(b)], \\
& \mu(\alpha) \cup \mu(b)=\max [\mu(\alpha), \mu(b)]
\end{aligned}
$$

4 operation. Value is defined $d_{j}^{*}$, which function of accessory is minimum

$$
\mu^{d_{j}}\left(x_{1}^{*}, x_{2}^{*}, x_{3}^{*}, \ldots, x_{n}^{*}\right)=\max _{j=1, m}\left[\mu^{d_{j}}\left(x_{1}^{*}, x_{2}^{*}, x_{3}^{*}, \ldots, x_{n}^{*}\right)\right]
$$

It will also be the recommended version of the decision for HDM which validity degree, corresponds to value of function of accessory $\mu^{d_{j}}\left(x_{1}^{*}, x_{2}^{*}, x_{3}^{*}, \ldots, x_{n}^{*}\right)$

Now we will consider the possibility of creating the algorithm of calculating temporary efficiency of processes of the decision-making support by means of the truncated procedures. At the same time it should be noted that after an assessment of decision-making validity the assessment of time and efficiency of decision-making processes is also very important.

According to work [7] where the principle of synthesizing the matrix of transitional probabilities (Markov's chains with two absorbing states) processes of decision-making support by means of the truncated procedures of type $(k / n)_{n}(k \leq n)$ are stated, and also expressions for calculating probabilities of efficiency are received.

Let's consider a technique and expressions of calculating conditional, unconditional population means and mean square values of times before decision-making (temporary efficiency) for procedures $(k / 4)_{4}(k=\overline{1,4})$, and also numerical calculation of temporary efficiency. Some other method the reader can find in Sailors et.al. [10], Box [14]

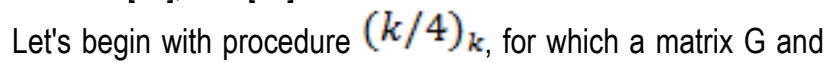
$S=N R$ have an appearance according to [7]

$$
\begin{gathered}
G=\left|\begin{array}{cccc}
0 & q & 0 & 0 \\
0 & 0 & q & 0 \\
0 & 0 & 0 & q \\
0 & 0 & 0 & 0
\end{array}\right|, \\
S=\left|\begin{array}{cc}
q^{4} & p\left(1+q+q^{2}+q^{3}\right) \\
q^{3} & p\left(1+q+q^{2}\right) \\
q^{2} & p(1+q) \\
q & p
\end{array}\right|
\end{gathered}
$$

From expression $N=(1-G)^{-1}[7,8,9]$ let's find expression for a functional matrix

$$
N=\left|\begin{array}{cccc}
1 & q & q^{2} & q^{3} \\
0 & 1 & q & q^{2} \\
0 & 0 & 1 & q \\
0 & 0 & 0 & 1
\end{array}\right| .
$$

From here expression for vectors $\overline{E V}$ and $\overline{H V}=(2 N-1) \overline{E V}-(\overline{E V})^{2}$ it is calculated as

$$
\begin{aligned}
& \overline{E V}=\left|\begin{array}{c}
\left(1+q+q^{2}+q^{3)}\right. \\
\left(1+q+q^{2}\right) \\
(1+q) \\
1
\end{array}\right| \\
& \overline{H V}=\left|\begin{array}{c}
q+3 q^{2}+3 q^{3}-q^{4}-2 q^{5}+q^{6}+q^{7} \\
3 q-2 q^{2}-q^{4}+4 q^{5} \\
q \bar{p} \\
0
\end{array}\right| .
\end{aligned}
$$


For receiving conditional population means $\overline{E V}$ and dispersions (mean square values $\overline{H V_{j}}(\overline{j=0,1}$ ) it is necessary to calculate matrixes $\widehat{G}_{z}$ and $\widehat{N}_{J}$. Therefore, making (taking into account a matrix (11)) calculations, we will receive taking into account (see in $[8,9])$ :

$$
\begin{aligned}
& \hat{G}_{0}=\left|\begin{array}{llll}
0 & 1 & 0 & 0 \\
0 & 0 & 1 & 0 \\
0 & 0 & 0 & 1 \\
0 & 0 & 0 & 0
\end{array}\right|,\left|\begin{array}{llll}
1 & 1 & 1 & 1 \\
0 & 1 & 1 & 1 \\
0 & 0 & 1 & 1 \\
0 & 0 & 0 & 1
\end{array}\right|, \\
& \overline{E V_{0}}=\left|\begin{array}{l}
4 \\
3 \\
2 \\
1
\end{array}\right| \overline{H V_{0}}=\left|\begin{array}{l}
0 \\
0 \\
0 \\
0
\end{array}\right|, \\
& \hat{G}_{1}\left|\begin{array}{cccc}
0 & \frac{q\left(1-q^{5}\right)}{1-q^{4}} & 0 & 0 \\
0 & 0 & \frac{q\left(1-q^{2}\right)}{1-q^{3}} & 0 \\
0 & 0 & 0 & \frac{q(1-q)}{1-q^{2}} \\
0 & 0 & 0 & 0
\end{array}\right|, \\
& =\left|\begin{array}{cccc}
0 & \frac{q\left(1-q^{3}\right)}{1-q^{4}} & \frac{q^{2}\left(1-q^{2}\right)}{1-q^{4}} & \frac{q^{2}(1-q)}{1-q^{4}} \\
0 & 1 & \frac{q\left(1-q^{2}\right)}{1-q^{2}} & \frac{q^{2}(1-q)}{1-q^{2}} \\
0 & 0 & 1 & \frac{q(1-q)}{1-q^{2}} \\
0 & 0 & 0 & 1
\end{array}\right| .
\end{aligned}
$$

Follows from a matrix (12)

$$
\overline{E V_{1}}=\left|\begin{array}{c}
\frac{\left(1+q+q^{2}+q^{3}-4 q^{4}\right)}{1-q^{4}} \\
\frac{\left(1+q+q^{2}-q q^{3}\right)}{1-q^{2}} \\
\frac{\left(1+q-2 q^{2}\right)}{1-q} \\
1
\end{array}\right|,
$$

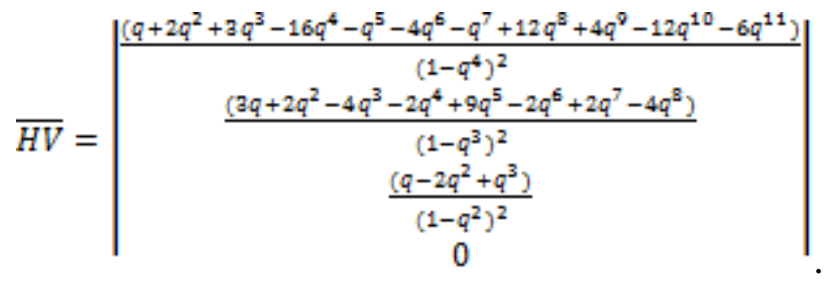

Let's pass to procedure $(2 / 4)_{4}$, for which a matrix $G$ and $S=N R$ have an appearance

$$
\begin{gathered}
G=\left|\begin{array}{cccccc}
0 & p & q & 0 & 0 & 0 \\
0 & 0 & p & q & 0 & 0 \\
0 & 0 & 0 & p & q & 0 \\
0 & 0 & 0 & 0 & 0 & q \\
0 & 0 & 0 & 0 & 0 & p \\
0 & 0 & 0 & 0 & 0 & 0
\end{array}\right|, \\
S=\left|\begin{array}{cc}
q^{2}(1+3 p) & p^{2}\left(1+2 q+3 q^{2}\right) \\
q^{a} & p\left(1+q+q^{2}\right) \\
q^{2}(1+2 p) & p^{2}(1+2 q) \\
q^{2} & p(1+q) \\
q(1+p) & p^{2} \\
q & p
\end{array}\right| .
\end{gathered}
$$

Fundamental matrix of procedure $(2 / 4)_{4} N=(1-Q)^{-1}$ after calculations on the basis of $[7,8,9,15]$ takes a form

$$
N=\left|\begin{array}{cccccc}
1 & p & q & 2 p q & q^{2} & 3 p q^{2} \\
0 & 1 & p & q & 2 p q & q^{2} \\
0 & 0 & 1 & p & q & 2 p q \\
0 & 0 & 0 & 1 & 0 & q \\
0 & 0 & 0 & 0 & 1 & p \\
0 & 0 & 0 & 0 & 0 & 1
\end{array}\right| .
$$

Taking into account a functional matrix (13) expression for unconditional vectors $\overline{E V}$ and $\overline{H V}=(2 N-1) \overline{E V}-(\overline{E V})^{2}$ [9] define as follows:

$$
\begin{aligned}
& \overline{E V}=\left|\begin{array}{c}
2(1+p q)+q^{2}(1+3 p) \\
1+q+q^{2} \\
2(1+p q) \\
1+q \\
1+p \\
1
\end{array}\right| \\
& \overline{H V}=\left|\begin{array}{c}
2 q+4 q^{2}-17 q^{3}+8 q^{4}+12 q^{5}-9 q^{6} \\
q+2 q^{2}-2 q^{3}+q^{4} \\
2 q-6 q^{2}+8 q^{3}+4 q^{4} \\
q-q^{2} \\
q-q^{2} \\
0
\end{array}\right|
\end{aligned}
$$

For calculation of conditions of vectors $\overline{E V}_{j}$ and $\overline{H V}_{j}(j=\overline{0,1})$ matrixes are necessary $\widehat{G}_{0}$ and $\widehat{G}_{1}$. On the matrix given in works $([7,9,15]$ calculated matrixes have an appearance:

$$
\hat{G}_{0}=\left|\begin{array}{cccccc}
0 & \frac{p}{1+1 q} & \frac{1+2 p}{1+1 q} & 0 & 0 & 0 \\
0 & 0 & 0 & 1 & 0 & 0 \\
0 & 0 & 0 & \frac{p}{1+2 q} & \frac{1+p}{1+2 q} & 0 \\
0 & 0 & 0 & 0 & 0 & 1 \\
0 & 0 & 0 & 0 & 0 & \frac{p}{1+p} \\
0 & 0 & 0 & 0 & 0 & 0
\end{array}\right|,
$$




$$
\hat{G}_{1}=\left|\begin{array}{cccccc}
0 & \frac{1+q+q^{2}}{1+2 q+1 q^{2}} & \frac{q(1+2 q)}{1+2 q+2 q^{2}} & 0 & 0 & 0 \\
0 & 0 & 0 & \frac{q(1+q)}{1+q+q^{2}} & 0 & 0 \\
0 & 0 & 0 & \frac{1+q}{1+2 q} & \frac{q}{1+2 q} & 0 \\
0 & 0 & 0 & 0 & 0 & \frac{q}{1+q} \\
0 & 0 & 0 & 0 & 0 & 1 \\
0 & 0 & 0 & 0 & 0 & 0
\end{array}\right| .
$$
8, 9]:

For procedure $(3 / 4)_{4}$ similar data are submitted in works [7,

$$
\begin{aligned}
& G=\left|\begin{array}{llllll}
0 & p & q & 0 & 0 & 0 \\
0 & 0 & p & q & 0 & 0 \\
0 & 0 & 0 & 0 & p & q \\
0 & 0 & 0 & 0 & 0 & q \\
0 & 0 & 0 & 0 & 0 & p \\
0 & 0 & 0 & 0 & 0 & 0
\end{array}\right|, \\
& S=\left|\begin{array}{cc}
q^{2}\left(1++2 p+3 p^{2}\right) & p^{2}(1+3 q) \\
q^{2}(1+2 p) & p^{2}(1+2 q) \\
q\left(1+p+p^{2}\right) & p^{a} \\
q^{2} & p(1+q) \\
q(1+p) & p^{2} \\
q & p
\end{array}\right|, \\
& N=\left|\begin{array}{cccccc}
1 & p & q & p^{2} & 2 p q & 3 p q^{2} \\
0 & 1 & 0 & p & q & 2 p q \\
0 & 0 & 1 & 0 & p & p^{2} \\
0 & 0 & 0 & 1 & 0 & q \\
0 & 0 & 0 & 0 & 1 & p \\
0 & 0 & 0 & 0 & 0 & 1
\end{array}\right|, \\
& \overline{E V}=\left|\begin{array}{c}
2(1+p q)+q^{2}(1+3 p) \\
2(1+p q) \\
1+p+p^{2} \\
1+q \\
1+p \\
1
\end{array}\right| \\
& \overline{H V}=\left|\begin{array}{c}
2 q+4 q^{2}-17 q^{a}+8 q^{4}+12 q^{5}-9 q^{6} \\
q+2 q^{2}-2 q^{a}+q^{4} \\
2 q-6 q^{2}+8 q^{a}+4 q^{4} \\
p-p^{2} \\
p-p^{2} \\
0
\end{array}\right|
\end{aligned}
$$

Matrixes $\widehat{G_{0}}$ and $\widehat{G_{1}}$ are presented in the form:

$$
\hat{G}_{0}=\left|\begin{array}{cccccc}
0 & \frac{p(1+2 p)}{1+2 p+a p^{2}} & \frac{1+p+p^{2}}{1+2 p+a p^{2}} & 0 & 0 & 0 \\
0 & 0 & 0 & \frac{p}{1+2 p} & \frac{1+p}{1+2 p} & 0 \\
0 & 0 & 0 & 0 & \frac{p(1+p)}{1+p+p^{2}} & 0 \\
0 & 0 & 0 & 0 & 0 & 1 \\
0 & 0 & 0 & 0 & 0 & \frac{1}{1+p} \\
0 & 0 & 0 & 0 & 0 & 0
\end{array}\right|,
$$

$$
\hat{G}_{1}=\left|\begin{array}{cccccc}
0 & \frac{1+2 q}{1+1 q} & \frac{q}{1+q q} & 0 & 0 & 0 \\
0 & 0 & 0 & \frac{1+q}{1+2 q} & 0 & 0 \\
0 & 0 & 0 & 0 & 1 & 0 \\
0 & 0 & 0 & 0 & 0 & \frac{q}{1+q} \\
0 & 0 & 0 & 0 & 0 & 1 \\
0 & 0 & 0 & 0 & 0 & 0
\end{array}\right| .
$$

Expression for vectors $\overline{E V}_{j}$ and $\overline{H V}_{j}\left(j=\overline{0,1}_{\text {because of }}\right.$ bulkiness we will not bring.

Let's pass to the last procedure $(4 / 4)_{4}$. Matrixes $G$ and $B$ have an appearance according to [7]:

$$
G=\left|\begin{array}{llll}
0 & p & 0 & 0 \\
0 & 0 & p & 0 \\
0 & 0 & 0 & p \\
0 & 0 & 0 & 0
\end{array}\right|, B=\left|\begin{array}{cc}
q\left(1+p+p^{2}+p^{\mathrm{a}}\right) & p^{4} \\
q\left(1+p+p^{2}\right) & p^{\mathrm{a}} \\
q(1+p) & p^{2} \\
q & p
\end{array}\right| .
$$

Matrixes $N$ and vectors $\overline{E V}$ and $\overline{H V}$ it is possible to present in the form $[6,7,8]$

$$
\begin{aligned}
& P=\left|\begin{array}{cccc}
1 & p & p^{2} & p^{\mathrm{a}} \\
0 & 1 & p & p^{2} \\
0 & 0 & 1 & p \\
0 & 0 & 0 & 1
\end{array}\right| \overline{E V}=\left|\begin{array}{c}
1+p+p^{2}+p^{\mathrm{a}} \\
1+p+p^{2} \\
1+p \\
1
\end{array}\right| \\
& \overline{H V}=\left|\begin{array}{c}
p+3 p^{2}+3 p^{2}-p^{4}-2 p^{5}+p^{6}+6 p^{7} \\
3 p-2 p^{2}-p^{4}+4 p^{5} \\
p q \\
0
\end{array}\right|
\end{aligned}
$$

By the matrix technique stated above and are calculated on formulas

$$
\begin{aligned}
\widehat{G}_{0} & =\left|\begin{array}{cccc}
0 & \frac{p\left(1-p^{\mathrm{s}}\right)}{1-p^{4}} & 0 & 0 \\
0 & 0 & \frac{p\left(1-p^{2}\right)}{1-p^{\mathrm{s}}} & 0 \\
0 & 0 & 0 & \frac{p(1-p)}{1-p^{2}} \\
0 & 0 & 0 & 0
\end{array}\right|, \\
& =\left|\begin{array}{llll}
0 & 1 & 0 & 0 \\
0 & 0 & 1 & 0 \\
0 & 0 & 0 & 1 \\
0 & 0 & 0 & 0
\end{array}\right| .
\end{aligned}
$$

Functional matrixes $\widehat{N_{j}}=\left(1-G_{j}\right)^{-1}(j=\overline{0,1})$ define by matrixes (14) as 


$$
\begin{aligned}
& =\left|\begin{array}{cccc}
1 & \frac{p\left(1-p^{\mathrm{B}}\right)}{1-p^{4}} & \frac{p^{2}\left(1-p^{2}\right)}{1-p^{4}} & \frac{p^{\mathrm{B}}(1-p)}{1-p^{4}} \\
0 & 1 & \frac{p\left(1-p^{2}\right)}{1-p^{\mathrm{B}}} & \frac{p^{\mathrm{D}}(1-p)}{1-p^{\mathrm{B}}} \\
0 & 0 & 1 & \frac{p(1-p)}{1-p^{2}} \\
0 & 0 & 0 & 1
\end{array}\right| \\
& =\left|\begin{array}{llll}
1 & 1 & 1 & 1 \\
0 & 1 & 1 & 1 \\
0 & 0 & 1 & 1 \\
0 & 0 & 0 & 1
\end{array}\right|
\end{aligned}
$$

Vectors $\overline{E V_{j}}(j=\overline{0,1})$, using matrixes (15), consider according to formulas:

$$
\overline{E V_{0}}=\left(\begin{array}{c}
\frac{1+p+p^{2}+p^{3}+p^{4}}{1-p^{4}} \\
\frac{1+p+p^{2}-3 p^{3}}{1-p^{3}} \\
\frac{1+p-2 p^{2}}{1-p^{2}} \\
1
\end{array}\left|\overline{E V_{1}}=\right| \begin{array}{l}
4 \\
3 \\
2 \\
1
\end{array} \mid .\right.
$$

We will present vectors of conditional dispersions in the form:

$$
\begin{aligned}
& \overline{H V_{0}}=\left|\begin{array}{c}
\frac{p+2 p^{2}+3 p^{3}-16 p^{4}-p^{5}+4 p^{6}-p^{7}+12 p^{8}+4 p^{0}-12 p^{10}-5 p^{11}}{\left(1-p^{4}\right)} \\
\frac{a p-2 p^{2}-4 p^{3}-2 p^{4}+9 p^{5}-2 p^{6}+2 p^{7}-4 p^{8}}{\left(1-p^{3}\right)^{2}} \\
\frac{p-2 p^{2}-3 p^{3}}{\left(1-p^{2}\right)^{2}} \\
0
\end{array}\right|, \\
& \overline{H V_{1}}=\left|\begin{array}{l}
0 \\
0 \\
0 \\
0
\end{array}\right| .
\end{aligned}
$$

Thus, all necessary expressions for calculation of temporary efficiency of processes of decision-making support by means of procedures of type $(K / 4)_{4}$ are received.

Let's bring also calculated on the expressions received above given to temporary efficiency for all procedures at $p=0,1\left(\delta V_{k}=+\sqrt{H V_{k}}\right)$ (tab. 1 and tab. 2).

\begin{tabular}{|c|c|c|c|c|}
\hline \multirow{2}{*}{$\begin{array}{l}\text { Vector of a } \\
\text { population } \\
\text { mean }\end{array}$} & \multicolumn{4}{|c|}{ Procedure } \\
\hline & $(1 / 4)_{4}$ & $(2 / 4)_{4}$ & $(3 / 4)_{4}$ & $(4 / 4)_{4}$ \\
\hline$\overline{E V_{0}}$ & $\begin{array}{l}2,3687 \\
1,9299 \\
1,4737 \\
1,00\end{array}$ & $\begin{array}{l}3,2734 \\
1,9299 \\
2,6429 \\
1,4737\end{array}$ & $\begin{array}{l}3,7297 \\
2,6429 \\
3,00 \\
1,4737\end{array}$ & $\begin{array}{l}4 \\
3 \\
2 \\
1\end{array}$ \\
\hline$\overline{E V_{1}}$ & $\begin{array}{l}4 \\
3 \\
2 \\
1\end{array}$ & $\begin{array}{l}3,23028 \\
3,00 \\
2,16677 \\
2,00 \\
1,09092 \\
1,00\end{array}$ & $\begin{array}{l}2,2113 \\
2,1667 \\
1,1081 \\
2,00 \\
1,0909 \\
1,00\end{array}$ & $\begin{array}{l}1,1107 \\
1,1081 \\
1,0909 \\
1,00\end{array}$ \\
\hline$\overline{E V}$ & $\begin{array}{l}2,439 \\
2,711 \\
1,90 \\
1,00\end{array}$ & $\begin{array}{l}3,233 \\
2,71 \\
2,17 \\
1,90 \\
1,10 \\
1,00\end{array}$ & $\begin{array}{l}2,217 \\
2,18 \\
1,11 \\
1,90 \\
1,90 \\
1,00\end{array}$ & $\begin{array}{l}1,111 \\
1,11 \\
1,10 \\
1,00\end{array}$ \\
\hline
\end{tabular}

The provided data allows to compare quantitatively among themselves various procedures and to choose the best of them

\begin{tabular}{|c|c|c|c|c|}
\hline \multirow{2}{*}{$\begin{array}{l}\text { Vector of a mean } \\
\text { square deviation }\end{array}$} & \multicolumn{4}{|c|}{ Procedure } \\
\hline & $(1 / 4)_{4}$ & $(2 / 4)_{4}$ & $(3 / 4)_{4}$ & $(4 / 4)$ \\
\hline$\overline{\delta V_{0}}$ & $\begin{array}{l}1,1128 \\
0,8142 \\
0,4903 \\
0\end{array}$ & $\begin{array}{l}0,7623 \\
0,8142 \\
0,4702 \\
0,4993 \\
0 \\
0\end{array}$ & $\begin{array}{l}0,4441 \\
0,4791 \\
0 \\
0,4993 \\
0 \\
0\end{array}$ & $\begin{array}{l}0 \\
0 \\
0 \\
0\end{array}$ \\
\hline$\overline{\delta V_{1}}$ & $\begin{array}{l}0 \\
0 \\
0 \\
0\end{array}$ & $\begin{array}{l}0,4113 \\
0 \\
0,3703 \\
0 \\
0,2875 \\
0\end{array}$ & $\begin{array}{l}0,4642 \\
0,3727 \\
0,3383 \\
0 \\
0,2875 \\
0\end{array}$ & $\begin{array}{l}0,349 \\
0,3382 \\
0,2875 \\
0\end{array}$ \\
\hline$\overline{\delta V}$ & $\begin{array}{l}1,0131 \\
0,6371 \\
0,30 \\
0\end{array}$ & $\begin{array}{l}0,4458 \\
0,6371 \\
0,3802 \\
0,30 \\
0,30 \\
0\end{array}$ & $\begin{array}{l}0,4732 \\
0,3842 \\
0,3433 \\
0,30 \\
0,30 \\
0\end{array}$ & $\begin{array}{l}0,3503 \\
0,3433 \\
0,30 \\
0\end{array}$ \\
\hline
\end{tabular}
proceeding from a specific practical objective.

Tab. 1. Values of conditional population means
Tab. 2. Values of conditional mean square deviations

\section{Conclusions}

At the organization of dialogue all possible versions of the decision and corresponding or functionating accessory, as a rule, are displayed that stimulates analytical opportunities of the person making the decision at decision-making process and does not limit its initiative.

The received decisions and expressions allow as the person making the decision and as the system of decision-making support to carry out an assessment of validity and to time efficiency of decision-making processes.

\section{Summary}

Decisions and expressions which allow as the person making the decision and decision-making support system, to carry out an assessment of validity and time efficiency relating to decisionmaking processes are provided in article. There are considered the principle of synthesizing the matrix of transitional probabilities, processes of decision-making support by means of the truncated procedures of type $(K / n)_{n}(K \leq n)$. All necessary expressions for calculation of temporary efficiency of processes of decision-making support by means of procedures of type $(K / 4)_{4}$ are shown. The calculated expressions enable a quantitative comparison between different procedures and select the best of them on the basis of specific practical tasks.

\section{References:}

1. Герасимов Б.М., Тарасов В.А., Токарев И.В. Человекомашинные системы принятия решений с элементами искусственного интеллекта - К: Наукова думка, 1993. - 183с. (in Russian: Gerasimov B.M., Taracov V.A., Tokarev I.V., Manmachine Decision-making Systems with Elements of Artificial Intelligence)

2. Гвардейцев М.И., Морозов В.П., Розенберг В.Я. Специальное математическое обеспечение управления. М.: Сов. радио, 1979. - 534 с. (in Russian: Gvardiencev M.I., Morozov V.P., Rozenberg V.J., Special Management Software)

3. Герасимов Б.М., Самохвалов Ю.Я., Методы оценки обоснованности решений в интеллектуальных системах: // Сучасні інформаційні технології у сфері безпеки та оборони №2(5), 2009. - C. 9-12. (in Russian: Gerasimov B.M., Camochvalov Yu.J., Assessment Methods of Decision Validity in Control Systems// Modern Information Technologies in the Sphere of Security and Defenñe 2(5)/2009) 
4. D.R., Cox, N., Reid, The Theory of the Design of Experiments, 2000, New York, Chapman and Hall/CRC, p. 336, ISBN : 9781420035834

5. D.K. Anand, Introduction to Control Systems, 1984 Elsevier Ltd., ISBN: 978-0-08-030001-6, p.448,

6. Ротштейн А.П. Интеллектуальные технологии идентификации - Винница: Универсум, 1991. - 320 с.(in Russian: Rotshtein A.P., Intelligent Identification Technologies)

7. Яншин В.В., Лисицын В.М. Синтез и вероятностный анализ усеченных процедур в задаче обработки информации по данным нескольких обзоров // Вопросы радиоэлектроники. Сер. «Общие вопросы радиоэлектроники». - Вып.1, 1986. C. 72-82. (in Russian: Janshin V.V., Lisicyn V.M., Synthesis and probabilistic analysis of truncated procedures in the task of processing information according to several surveys)

8. P. L., de Castro; G. A., Braz; C. Á., Bruno, Using Information Systems to strategic decision: an analysis of the values added under executive's perspective // Brazilian Journal of Information Studies: Research Trends, Vol. 11:1 (2017) p.54-71 ISSN 1981 1640.

9. N., Privault, Understanding Markov Chains, Examples and Applications, p. 354, 2013, Springer Singapore, ISBN: 978-9814451-51-2

10. R. M. Sailors, T. D. East, C. J. Wallace, D. A. Carlson, M. A. Franklin, L. K. Heermann, A. T. Kinder, R. L. Bradshaw, A. G. Randolph, and A. H. Morris, Testing and validation of computerized decision support systems, Proc AMIA Annu Fall Symp. 1996 : 234-238. PMCID: PMC2233208
11. L., Pronzato, Optimal experimental design and some related control problems, Automatica, Vol. 44(2), 2008, pp. 303-325

12. J.C., Pomerol, Artificial intelligent and human decision making, European Journal of Operational Research Vol. 99, 1997, pp. 325

13. R. L., Kumar, Understanding DSS value: an options perspective, Omega, Vol. 27(3), 1999, pp. 295-304, Elsevier

14. Box, G. E.P.; Hunter, W. G.; Hunter, J. S., (2005). Statistics for Experimenters : Design, Innovation, and Discovery (2 ed.), Hoboken, N.J.: Wiley, ISBN 978-0471718130

15. Nadiia Vasylkiv, Lesia Dubchak, Taras Lendyuk, Iryna Turchenko, Inna Shylinska, Marek Aleksander; Tasks Distribution for Students Testing Based on Fuzzy Logic; The 9th IEEE International Conference on Intelligent Data Acquisition and Advanced Computing Systems: Technology and Applications 21-23 September 2017

Authors:

DSc, PhD, professor Oleksandr Petrov - AGH University of Science and Technology, asp1951@gmail.com

DSc, PhD, professor Volodymyr Horoshko - National Aviation University, Ukraine, professor_va@ukr.net

DSc, PhD Marek Aleksander - Podhale State College of Applied Sciences in Nowy Targ, aleksandermarek4@gmail.com

PhD Beata Basiura - AGH University of Science and Technology, bbasiura@zarz.agh.edu.pl

PhD Yulia Hokhlacheva - National Aviation University, Ukraine, professor_va@ukr.net 